\title{
The effects of the mGluR5 receptor antagonist 6-methyl-2-(phenylethynyl)-pyridine (MPEP) on behavioural responses to nicotine
}

\author{
Valeria Tronci • Svetlana Vronskaya • \\ Nicholas Montgomery • Daniela Mura • \\ David J. K. Balfour
}

Received: 19 February 2010 /Accepted: 10 April 2010/Published online: 27 April 2010

(C) The Author(s) 2010. This article is published with open access at Springerlink.com

\begin{abstract}
Rationale Previous studies have shown that blockade of metabotropic glutamate 5 receptors (mGluR5) results in inhibition of nicotine self-administration in experimental animals. However, these studies have not established the behavioural mechanisms which mediate these effects or the extent to which the effects of mGluR5 antagonism on nicotine self-administration reflect a selective attenuation of nicotine reinforcement.

Objectives To investigate the effects of antagonising mGluR5 receptors on psychopharmacological responses to nicotine measured using conditioned and unconditioned behaviours.

Results 2-Methyl-6-(phenylethynyl)-pyridine (MPEP) significantly $(P<0.01)$ reduced nicotine self-administration and attenuated $(P<0.01)$ the ability of non-contingent nicotine to enhance the reinforcing properties of a weak reinforcer (extinguishing the house light in an operant chamber). It also attenuated $(P<0.05)$ the much lower levels of responding for this reinforcer measured in control animals treated with saline. MPEP did not attenuate the increase in locomotor activity induced by acute and repeated nicotine in animals habituated on the test day to the test environment. Furthermore, it had no significant effects on responding for a palatable food reward. By contrast, MPEP significantly reduced $(P<0.001)$ conditioned locomotor stimulation evoked by pairing nicotine with a specific environment.
\end{abstract}

V. Tronci $(\bowtie) \cdot$ S. Vronskaya $\cdot$ N. Montgomery $\cdot$ D. Mura

D. J. K. Balfour

Centre for Neuroscience, Division of Medical Sciences,

Mail Point 5, University of Dundee Medical School,

Ninewells Hospital,

Dundee DD1 9SY, UK

e-mail: v.tronci@dundee.ac.uk
Conclusion The results are consistent with the hypothesis that mGluR5 receptors play an important role in mediating the effects of contextual cues in conditioned behavioural responses to nicotine.

Keywords Nicotine $\cdot$ Self-administration .

Locomotor activity

\section{Introduction}

It is now widely accepted that nicotine has the properties of a drug of dependence and that it is the major addictive component of tobacco smoke (Henningfield et al. 2009; Benowitz 2009). Surprisingly, however, in intravenous selfadministration studies with rodents, nicotine is a relatively weak reinforcer when it is administered alone, and these weak reinforcing properties do not seem to provide an adequate explanation for the powerful addiction to tobacco experienced by many habitual smokers (Caggiula et al. 2001; Balfour 2006). However, the acquisition of nicotine self-administration is enhanced significantly if a stimulus, such as a tone and/or a light, is associated with the delivery of each nicotine infusion (Caggiula et al. 2001; Cohen et al. 2005). By association with nicotine, the stimulus acquires the properties of a conditioned stimulus which is sufficiently reinforcing to maintain nicotine-seeking behaviour in the absence of nicotine for an extended period of time (Caggiula et al. 2001; Chaudhri et al. 2006a; Cohen et al. 2005). Additionally, nicotine has the ability to enhance the reinforcing properties of stimuli which are, when delivered alone, only weakly reinforcing, and it has been suggested that this property of the drug also plays a significant role in the psychobiology underpinning addiction to the drug 
(Caggiula et al. 2001; Chaudhri et al. 2006a, b; Balfour 2006). Thus, these data support the hypothesis that dependence upon tobacco may reflect an interaction between nicotine and stimuli associated with its availability and delivery.

The neurobiological mechanisms which mediate conditioned responding to nicotine have been the subject of relatively few studies. However, experiments with other psychostimulant drugs have implicated glutamatergic systems in drug-seeking behaviour evoked by conditioned stimuli (Burns et al. 1994; You et al. 2007; Crombag et al. 2008). Furthermore, there is a growing body of evidence that the role of glutamate in conditioned responding may depend to a significant degree upon the stimulation of mGluR5 receptors (Martin-Fardon et al. 2009; Bäckström and Hyytiä 2007). There is also evidence that mGluR5 receptors play a role in nicotine selfadministration and in the cue-induced reinstatement of nicotine-seeking behaviour (Paterson et al. 2003; Tessari et al. 2004; Palmatier et al. 2007). The role of mGluR5 receptors in the more complex mechanisms thought to underpin nicotine dependence is less clear. In this study therefore, the non-competitive mGluR5 receptor antagonist 2-methyl-6-(phenylethynyl)-pyridine (MPEP) has been examined for its effects on both contingent and non-contingent behavioural responses to nicotine. The primary aim of the study was to explore the extent to which mGluR5 receptors may be implicated in the role of environmental and contextual cues in conditioned responding to nicotine.

\section{Materials and methods}

Animals

The experiments were performed using male SpragueDawley rats (Harlan UK). The rats weighed approximately 250-270 $\mathrm{g}$ at the beginning of each experiment and were housed in a temperature- and humidity-controlled vivarium $\left(21^{\circ} \mathrm{C} ; 55 \%\right.$ humidity), in which the lights were on between 06:00 and 18:00 h daily. For the self-administration studies, the animals were housed singly. For the other studies, the rats were house in groups of four. For all the operant studies, food (standard laboratory chow) was restricted to $20 \mathrm{~g}$ per day, a protocol which maintained the rat weights at approximately $90 \%$ of free-feeding weight. All the experiments were performed under the auspices of UK Home Office licence PPL 60/1375.

Nicotine intravenous self-administration studies

The rats $(n=21)$ were trained in $1-\mathrm{h}$ sessions to lever press (for half the rats, the left lever was active; for the remainder, the right lever was active) in standard twolever operant chambers (MED Associate Inc.) on a fixed ratio 1 with a $20 \mathrm{~s}$ timeout (FR1:TO20) schedule for a 45 $\mathrm{mg}$ sucrose pellet reinforcer. The house light was on during the session. During the timeout period, active lever pressing was recorded but did not have any programmed consequences. When the responding was stable (for three consecutive sessions, the variability of the number of responses on the active lever was less than $20 \%$, and stable intake of food was reached), rats were transferred to the FR3:TO20 schedule of reinforcement and stableresponding re-established.

After acquiring the operant behaviour, rats were anaesthetised with $5 \%$ isofluorene in $2 \%$ of oxygen and implanted with chronic silastic catheters (Camcaths, Cambridge UK) in the jugular vein. Carprofen (Pfizer; $5 \mathrm{mg}$ / $\mathrm{kg}$, s.c.) was used as the analgesic during the surgery. For the 6 days following surgery, the animals were given Timentin (GSK; $60 \mathrm{mg}$, i.v. in $100 \mu \mathrm{l}$ ) prophylactically, and the catheters were flushed daily with heparin ( $3 \mathrm{U}$ in $0.1 \mathrm{ml}$ ) daily. The animals were given $7-10$ days to recover from the surgery before commencing with nicotine self-administration. During nicotine self-administration, the catheters were flushed with heparin before and after each session.

Intravenous nicotine self-administration (IVSA) was under an FR3:TO20 schedule of reinforcement. The active lever previously associated with food delivery was paired with the delivery of nicotine $(0.03 \mathrm{mg} / \mathrm{kg} /$ infusion $)$ delivered in a volume of $60 \mu \mathrm{l}$ in $3.2 \mathrm{~s}$. Responding on the inactive lever was recorded but did not have any programmed consequences. The delivery of the nicotine infusion was paired with a 20 -s cue light located above the active lever and a 1-s tone (Cohen et al. 2005). During the 20 -s timeout period, lever pressing on the active lever was recorded but did not have any programmed consequences. The session was terminated if a maximum of 30 nicotine infusions was reached or after $60 \mathrm{~min}$. Once the rats reached a stability criterion (less than $30 \%$ variability for the number of active press lever over three consecutive sessions), the effects of MPEP and its vehicle were tested for their effects on responding for nicotine. In 16 rats, three different intravenous doses of MPEP $2.5 \mathrm{mg} / \mathrm{kg}(N=8)$, MPEP $5 \mathrm{mg} / \mathrm{kg}(N=4)$ and MPEP $10 \mathrm{mg} / \mathrm{kg}(N=4)$ and saline were tested. The drug was always delivered in a volume of $0.1 \mathrm{ml}$ (equivalent to approximately $0.33 \mathrm{ml} / \mathrm{kg}$ ). MPEP 5 and $2.5 \mathrm{mg} / \mathrm{kg}$ or its saline vehicle was also administered (i.p.) using a counter-balanced design in five additional rats trained to respond for nicotine. Each injection was separated by $48 \mathrm{~h}$, with a normal $1 \mathrm{~h}$ nicotine self-administration session on the intervening day. MPEP was administered $30 \mathrm{~min}$ before nicotine self-administration session. 
Response-enhancing effects of nicotine

The protocol was based on that described by Donny et al. (2003). Rats were initially trained to lever press on the right or left lever of a two-lever operant chamber for a sweetened pellet on a continuous schedule of reinforcement. The training sessions were terminated after $60 \mathrm{~min}$ or when the rats had received 100 reinforcers. The groups of rats were given s.c. injections of saline $(1 \mathrm{ml} / \mathrm{kg})$ or nicotine $(0.4 \mathrm{mg} /$ $\mathrm{kg}$ ) to habituate them to the injection, $2 \mathrm{~h}$ after each of the last five training sessions. Once responding was stable (the rats consistently received 100 sucrose pellets in $30 \mathrm{~min}$ ), the rats were transferred to an FR1:TO20 schedule of reinforcement. In this schedule, a correct lever-pressing response was reinforced by brief illumination ( $2 \mathrm{~s})$ of a stimulus light above the active lever and extinguishing the house light for $20 \mathrm{~s}$. The animals habituated to saline were given s.c. saline, $5 \mathrm{~min}$ prior to each session; those habituated to nicotine were given s.c. nicotine. Once responding was stable (the variation in responding was less than $30 \%$ over three consecutive days), the contingency was increased to FR2:TO20. In one experiment ( $N=6$ per group), this contingency was maintained for five daily sessions and then increased to FR5:TO20 for 5 days. In an experiment with a second group of rats ( $N=6$ per group), the animals were maintained on the FR2:TO20 schedule and used to investigate the effects of i.p. MPEP (2.5 and $5.0 \mathrm{mg} / \mathrm{kg}$ ) and saline on lever pressing using a counterbalanced design. In a minimum of three operant sessions intervened between the test days, the animals receiving their habitual treatment (saline or nicotine) on the intervening days.

\section{Food-reinforced behaviour}

The rats were initially trained to respond for a sweetened food reward in the same operant chambers used for nicotine self-administration under a FR1:TO20 schedule of reinforcement. The schedule was changed to a FR3:TO20s when rats had acquired the previous schedule. Delivery of the reinforcer was coupled with the same conditioned stimulus (stimulus light on for $20 \mathrm{~s}$; tone $1 \mathrm{~s}$ ) as that used for the nicotine self-administration studies. Once responding for food was stable, drug testing was initiated. MPEP $5 \mathrm{mg} / \mathrm{kg}$ (i.p.) or its saline vehicle was administered $30 \mathrm{~min}$ before the test session using a counter-balanced design.

\section{Locomotor activity experiments}

Twenty-four rats were divided in four groups of six rats each. On day 1 , the effects of MPEP $5 \mathrm{mg} / \mathrm{kg}$ on the locomotor responses to acute nicotine $(0.4 \mathrm{mg} / \mathrm{kg}$, s.c. $)$ or saline were investigated. Each rat was placed in a 4-arm maze (each arm was $42 \mathrm{~cm}$ long $\times 14 \mathrm{~cm}$ across with $30 \mathrm{~cm}$ high sides) for $30 \mathrm{~min}$ to habituate them to the maze. The rats were then given i.p. injections of saline or MPEP and $30 \mathrm{~min}$ later by nicotine $(0.4 \mathrm{mg} / \mathrm{kg}$, s.c. $)$ or saline. Activity (entries in the arms) was recorded every 10 min throughout and for $20 \mathrm{~min}$ after the s.c. injection. The animals previously injected with nicotine or saline were respectively given daily injections of nicotine (nicotine-pretreated) or saline (saline-pretreated) in their home cage on days $2-8$; on day 9 , no treatment were given. On day 10 , the effects of MPEP on the locomotor responses to nicotine (in nicotinepretreated rats) or saline (saline-pretreated rats) were again investigated using a protocol identical to that employed on day 1.

\section{Conditioned locomotor experiments}

Rats were assigned to one of two groups. One group (maze paired group) was treated with daily s.c. of saline $(N=6)$ or nicotine $(0.4 \mathrm{mg} / \mathrm{kg} ; N=6)$ for 16 days, and $5 \mathrm{~min}$ after each injection, they were placed in the four-arm cross maze for 15 min. Activity (arm entries) was recorded on days 1, 5, 10, and 15. A second group of rats (maze unpaired group) were also treated with s.c. saline $(N=6)$ or nicotine $(0.4 \mathrm{mg} /$ $\mathrm{kg} ; N=6$ ) for 16 days but were returned to their home cages after each injection. On days 17 and 21, the rats were pretreated with saline or MPEP $(5 \mathrm{mg} / \mathrm{kg})$ using a counterbalanced design $30 \mathrm{~min}$ prior to an injection of saline, and the activity was tested for $15 \mathrm{~min}$ starting $5 \mathrm{~min}$ after the second injection. On the intervening days, the animals received their habitual injections of saline or nicotine and were placed in the maze as usual or were returned to their home cages. On days 26 and 30, the effects of pretreating the animals with MPEP or saline were also investigated in rats which received their habitual injection of nicotine 5 min prior to testing in the maze.

\section{Drugs}

(-)-Nicotine hydrogen tartrate (Sigma Aldrich) was dissolved in saline and neutralised with $0.1 \mathrm{~N} \mathrm{NaOH}$. Noncontingent injections of the drug were delivered in volume of $1 \mathrm{ml} / \mathrm{kg}$. The doses are expressed in terms of the free base. MPEP (Sigma Aldrich) was also dissolved in saline. Intravenous injections were given in a volume of $0.1 \mathrm{ml}$. Intraperitoneal injections were delivered in a volume of $1 \mathrm{ml} / \mathrm{kg}$.

Data analysis

All results are reported as means \pm SEM. For the IVSA experiment, the data were analysed using an ANOVA for repeated measures with treatment on the test day and active 
versus inactive lever responses as the within subjects variable. Post hoc analyses were performed using paired $t$ tests. For the other operant studies, a two-way ANOVA for repeated measures was used using habitual treatment as the between-subject variable with pretreatment on the test day and active versus inactive lever responses as the withinsubject variables. Post hoc analyses were performed using paired $t$ tests. In the first response-enhancing study, contingency was used as an additional within-subject variable. The data derived from the locomotor studies using the cross maze were also analysed using a two-way ANOVA with habitual treatment (saline or nicotine) and test treatment as the between-subject factors and days of treatment as the within-subject variable. In the studies on conditioned locomotor responding, two-way ANOVA for repeated measures was also employed. Habitual treatment (saline or nicotine) and habituation/no habituation to the maze were the between-subject factors analysed; pretreatment on the test day was the within-subject factor.

\section{Results}

\section{Operant experiments}

Using the paradigm adopted for this study, rats consistently pressed on the active lever for nicotine at a rate which was significantly higher $(F(1,8)=47.76, P<0.001)$ than responding on the inactive lever (Fig. 1). On the test days,

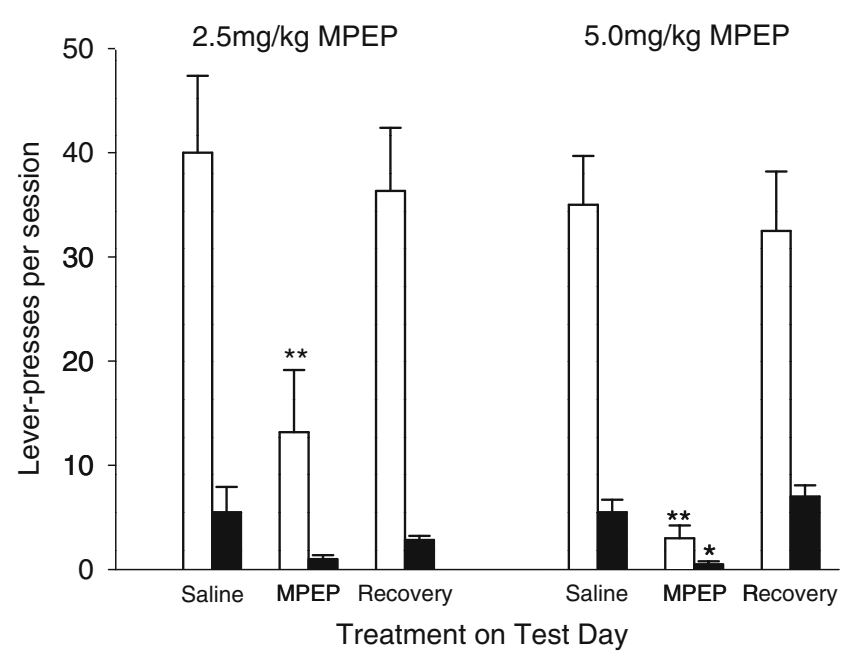

Fig. 1 The effects of intravenous MPEP on operant responding for nicotine. Rats were trained to lever-press for nicotine on an FR3 schedule of reinforcement with a 20 -s timeout. The figure shows mean responding on the active lever (open columns) and the inactive lever (filled columns) for rats pretreated with saline or MPEP ( $N=8$ for $2.5 \mathrm{mg} / \mathrm{kg} ; N=4$ for $5.0 \mathrm{mg} / \mathrm{kg}$ ) prior to the session. Data for the day after the MPEP session are also presented. The data are reported as means \pm SEM. Significantly different from rats pretreated with saline $* P<0.05 ; * * P<0.01$ responding for nicotine was influenced by the treatment the animals received (treatment $\times$ lever $F(3,24)=31.98, P<$ 0.001). Post hoc analysis showed that treatment with MPEP $(2.5$ or $5.0 \mathrm{mg} / \mathrm{kg}$ ) reduced responding on both the active lever (treatment $F(1,8)=80.57, P<0.001$ ) and the inactive lever (treatment $F(1,8)=8.43, P<0.05$ ) when compared with the day on which the animals were given saline. The data suggest that the effects of MPEP were dose-dependent, although statistically, the response was not influenced by the dose of MPEP employed. The treatment on the test day had no significant effect on the performance of the rats on the day following treatment which returned to baseline levels. An intravenous injection of MPEP at a dose of $10 \mathrm{mg} / \mathrm{kg}$ resulted in complete inhibition of responding for nicotine in all of the rats tested.

The i.p. administration of MPEP $(2.5 \mathrm{mg} / \mathrm{kg})$ also attenuated responding for nicotine (treatment $\times$ lever $F$ $(3,12)=17.62, P<0.01)$. Post hoc analysis showed again that pretreatment with MPEP inhibited responding on both the active lever $(F(3,12)=0.87, P<0.001)$ and inactive lever $(F(3,12)=9.99, P<0.001)$. Pretreatment with MPEP $(5 \mathrm{mg} /$ $\mathrm{kg}$, i.p.) resulted in total inhibition of responding in all of the five rats tested. By contrast, $5 \mathrm{mg} / \mathrm{kg}$ MPEP had no significant effects on responding on the active lever for a palatable food reward (active lever presses after i.p. saline $=$ $209 \pm 35$; active lever presses after i.p. $\mathrm{MPEP}=183 \pm 35$ ).

The response-enhancing effects of subcutaneous nicotine were investigated using a protocol in which rats were trained to extinguish the house light. The pilot study showed that rats trained in this protocol preferentially pressed the active lever (lever $F(1,10)=65.1, P<0.001$; Fig. 2). Responding was significantly enhanced in nicotinetreated animals in a manner which was dependent upon the contingency (nicotine $\times$ contingency $F(2,20)=5.4, P<$ $0.05)$. Furthermore, nicotine preferentially enhanced responding on the active lever (lever $\times$ nicotine $F(1,10)=9.81$, $P<0.05)$. Post hoc analysis revealed a significant effect of nicotine on active lever responding in rats tested on the FR2 or FR5 schedules $(F(1,10)=17.23, P<0.01$ and $7.53, P<$ 0.05 , respectively). Nicotine also significantly enhanced responding on the inactive lever under the FR5 condition ( $F$ $(1,10)=6.65, P<0.05)$. The effects of MPEP were investigated in a second group of rats stably maintained on the FR2 schedule of reinforcement (Fig. 3). These experiments confirmed that nicotine preferentially enhanced responding on the active lever (lever $\times$ nicotine $F(1,10)=34.57, P<$ 0.001 ; post hoc analysis $P<0.001)$, although it also increased responding on the inactive lever $(P<0.05)$. Pretreatment with MPEP on the test day dose-dependently reduced responding on both levers in the saline- and nicotine-treated rats $(F(2,20)=37.1, P<0.001$ for the active lever; $F(2,20)=5.3, P<0.05$ for the inactive lever; Fig. 3). The effect of the MPEP injections in nicotine-treated rats on 


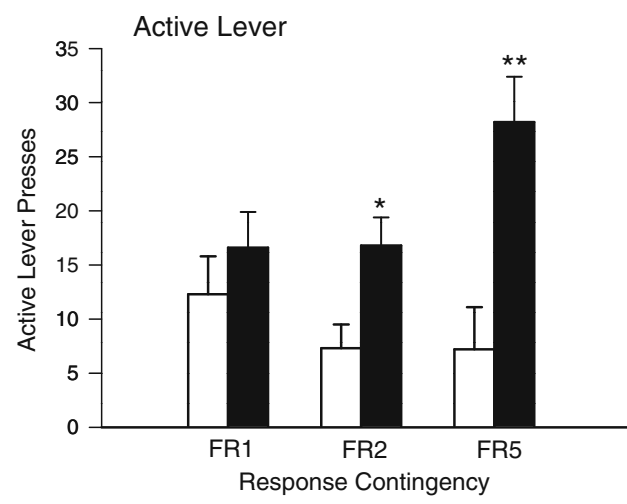

Fig. 2 The influence of contingency on the response-enhancing effects of nicotine. Groups of rats $(N=8$ in each group) were treated with daily injections of saline (open bars) or nicotine $(0.4 \mathrm{mg} / \mathrm{kg}$, s.c.; filled bars) and trained in an operant task reinforced by stimulus light above the active lever and extinguishing the house light. The bars

responding on the active lever was more highly significant than that measured in the saline-treated rats (nicotine $x$ MPEP $F(2,20)=10.3, P<0.001)$. The difference in the effects of MPEP on responding on the inactive lever between the saline- and nicotine-treated rats approached significance $(F(2,20)=3.0, P=0.073)$. Following completion of the experiments with MPEP, the lever which extinguished the light was switched from the one used during training to the lever on the opposite side of the box. Over a period of 14 days, responding on the active lever used during training decreased $(F(1,10)=23.7, P<0.001)$, whereas responding on the lever which was inactive during training increased $(F(1,10)=39.7, P<0.001$; Fig. 4$)$. In both cases, the effect was statistically more significant for the nicotine-treated rats (nicotine $\times$ days $F(1,10)=6.3, P<0.05$ for active to inactive; $F(1,10)=24.7, P<0.001$ for inactive to active).

Studies employing the cross maze

When exploration of the cross maze was investigated in rats which were allowed to habituate to the apparatus for $60 \mathrm{~min}$

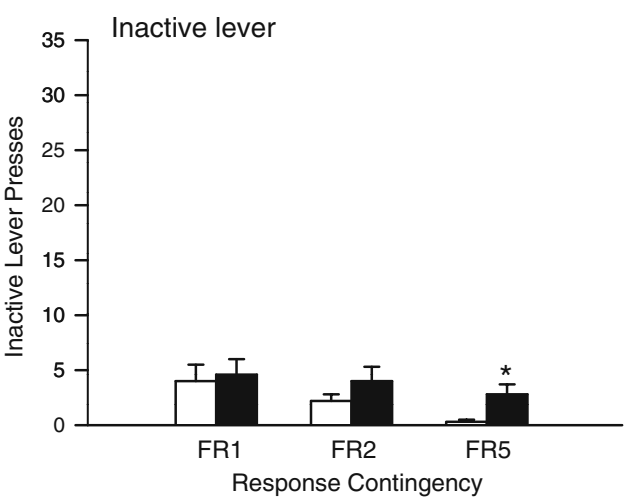

represent the means \pm SEM of the lever presses on the active and inactive levers when responding was reinforced using contingencies which increased from FR1:TO20 to FR5:TO20. Significantly different from rats injected with saline $* P<0.05 ; * * P<0.01$

(Fig. 5), the activity of the saline-treated rats was very low (mean $<5$ entries in $20 \mathrm{~min}$ ). When nicotine was tested for its effects on maze exploration in these rats, both acute and repeated administration of the drug increased entries into the arms of the maze (nicotine $F(1,20)=80.54, P<0.001$; Fig. 5). The response to nicotine was also influenced by pretreatment with the drug (nicotine $\times$ days $F(1,20)=5.60$, $P<0.05)$. Post hoc analysis showed that the stimulant response to nicotine was greater $(P<0.05)$ in the animals pretreated with the drug for 8 days prior to the test session. The responses to both acute and repeated nicotine were not influenced significantly by prior treatment with MPEP on the test day.

The final experiment explored the effects of nicotine and MPEP on initial activity in the cross maze measured during 15 min after the animals were placed in the maze. The activity of the rats, which were repetitively tested in the maze, was influenced significantly (treatment $\times$ sessions $F$ $(3,30)=12.99, P<0.001)$ by both treatment and the duration of treatment (Fig. 6). Post hoc analysis showed that nicotine reduced activity on day $1(P<0.001)$ from $33.0 \pm 1.9$ to 15.8 \pm 1.6 entries per $15 \mathrm{~min}$, whereas by day 15 , the activity of
Fig. 3 The effects of MPEP on the response-enhancing effects of nicotine. Saline and nicotine $(0.4 \mathrm{mg} / \mathrm{kg}$, s.c. $)$ treated rats ( $N=8$ in each group) were trained in an operant task (FR2: TO20) reinforced by a stimulus light above the active lever and extinguishing the house light. The bars represent means \pm SEM for the lever-pressing responses on the active lever (panel $A$ ) and the inactive lever (panel B)
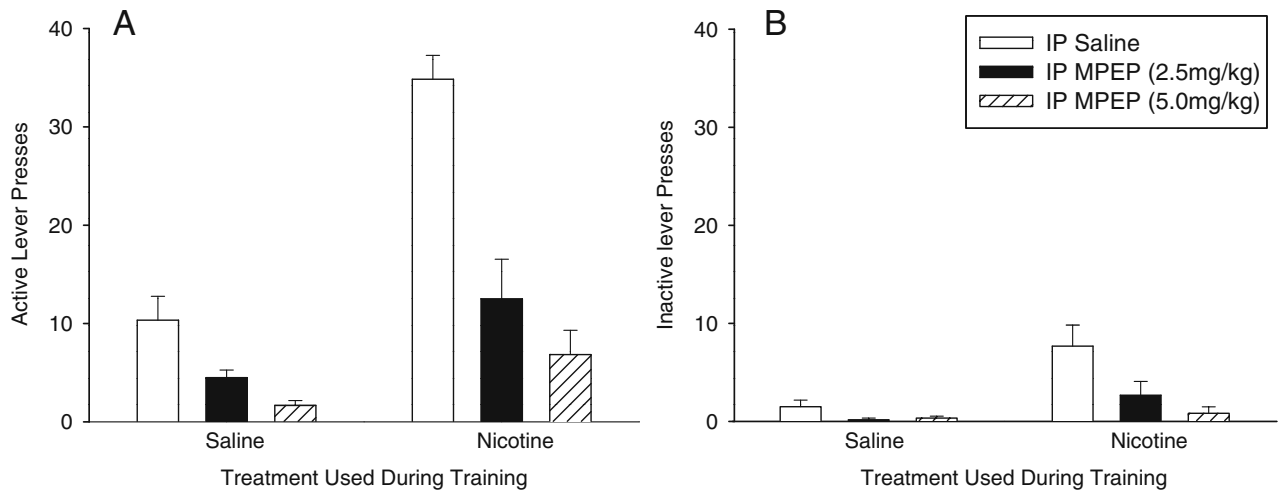


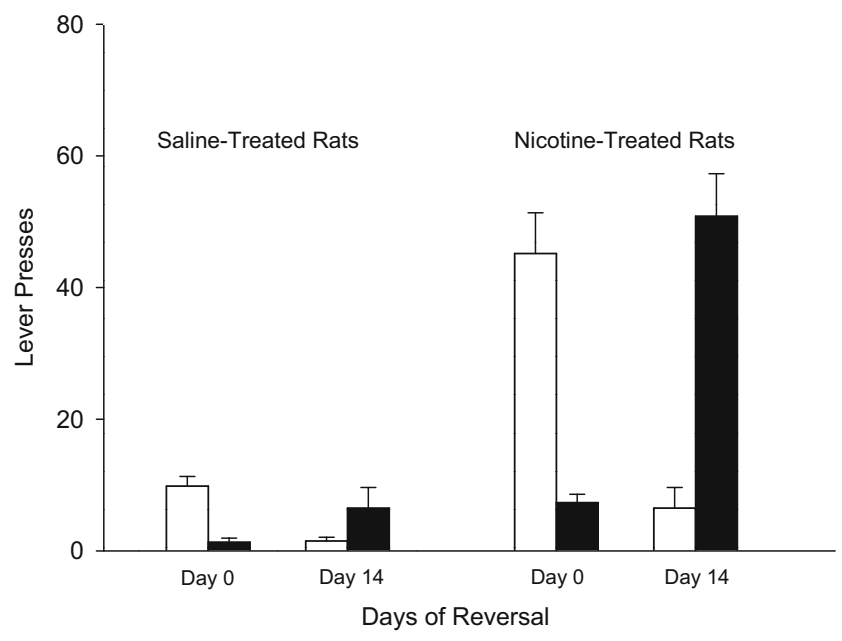

Fig. 4 The effects of lever reversal on operant responding reinforced by extinguishing the house light. Saline and nicotine $(0.4 \mathrm{mg} / \mathrm{kg}, \mathrm{s.c}$.) treated rats $(N=8$ in each group) were trained (FR2:TO20) to extinguish the house light by pressing either the left or the right lever of a two-lever operant chamber. The data are expressed as means \pm SEM and show responding on the lever used during training (open bars) and the non-training lever (filled bars). The data for day 0 represent the results for the last day on which responding was reinforced by the lever used during training. The data for day 14 represent the results for the 14th day on which the reinforcer was delivered when the rats pressed the alternate lever

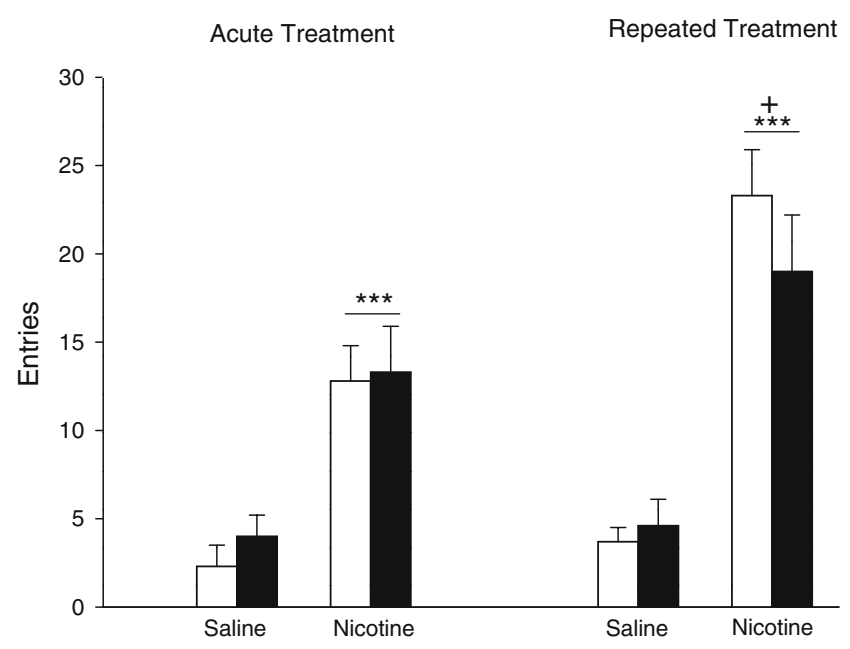

Fig. 5 The effects of nicotine and MPEP on activity in a cross maze. Groups of rats ( $N=6$ in each group) were treated with daily injections (s.c.) with saline or nicotine $(0.4 \mathrm{mg} / \mathrm{kg})$ for 8 days. Prior to the injection on day 1 , the rats were placed in a cross maze for $30 \mathrm{~min}$ before being given an i.p injection of MPEP $(5.0 \mathrm{mg} / \mathrm{kg}$; filled columns) or saline (open columns). Thirty minutes after the injection, the rats were given a second s.c. injection of saline or nicotine $(0.4 \mathrm{mg} / \mathrm{kg})$, and entries into the arms of the cross maze counted for $20 \mathrm{~min}$ starting immediately after the second injection (acute treatment). The procedure was repeated on day 10 (repeated treatment). The data are expressed as means \pm SEM. Significantly different from rats treated with s.c. saline ${ }^{* * *} P<0.001$; significantly different from rats tested after acute nicotine $+P<0.05$

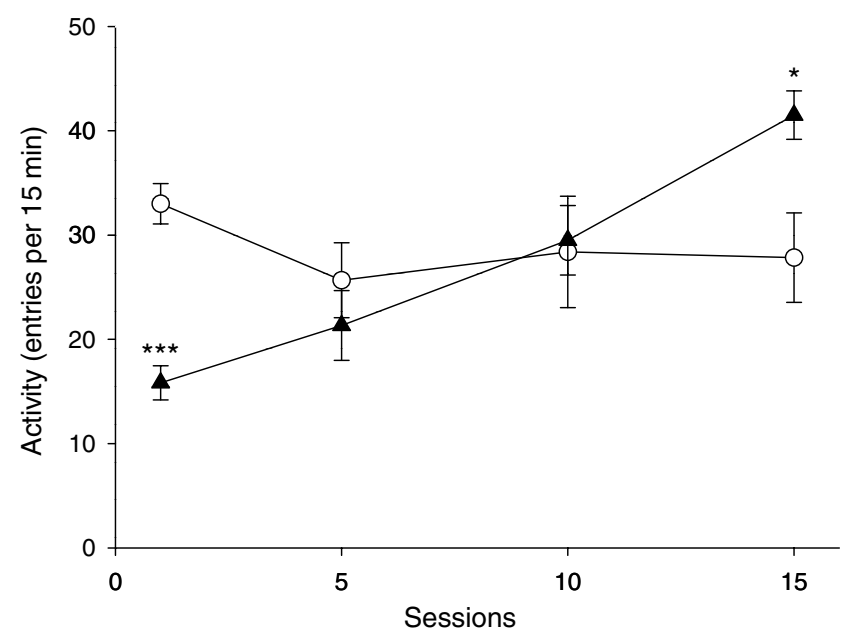

Fig. 6 The effects of repeated nicotine on activity in a cross maze. Groups of rats ( $N=6$ per group) were given daily s.c. injections of saline (open circles) or nicotine $(0.4 \mathrm{mg} / \mathrm{kg}$; filled triangles) and placed in the maze after each injection for $15 \mathrm{~min}$. The results are expressed as mean \pm SEM and represent the data for the days on which activity was recorded. Significantly different from saline-treated rats $* P<0.05 ; * * * P<0.001$

the nicotine-treated rats was significantly increased $(P<$ 0.05 ) from $27.8 \pm 4.3$ to $41.5 \pm 2.3$ entries per $15 \mathrm{~min}$ when compared with the saline-treated control animals. In the animals which had been repeatedly injected with saline or nicotine, there was a significant interaction between the effects of nicotine treatment on activity and prior experience of the maze (nicotine $\times$ habituation $F(1,20)=5.8, P<$ $0.05)$. Post hoc analysis revealed that repeated nicotine administration did not enhance the higher levels of locomotor activity measured in animals which had not been habituated to the apparatus by prior repeated exposure to the apparatus (Fig. 7). Furthermore, pretreatment with MPEP had no significant effects on the locomotor activity of either saline-treated or nicotine-treated rats tested in this way. By contrast, in the animals repeatedly exposed to the maze after each injection, nicotine stimulated activity $(P<$ 0.01). In these animals, the effects of MPEP depended upon treatment during the habituation phase of the experiment (nicotine $\times$ MPEP $F(1,10)=6.5, P<0.05$ ). Post hoc analysis showed that MPEP inhibited the activity of rats treated with nicotine (MPEP $F(2,10)=14.79, P<0.001$ ) but had no significant effects in the rats treated with saline. If the rats were habituated to the maze and were then tested in the maze following an injection of saline, there was a significant interaction between the effects of prior exposure to the maze and the treatment administered during the conditioning phase (nicotine $\times$ habituation $F(1,20)=12.5$, $P<0.01)$. In rats conditioned to the maze with nicotine, the number of entries made when they were subsequently tested after an injection of saline remained significantly higher $(P<0.01)$ than that recorded for animals conditioned 


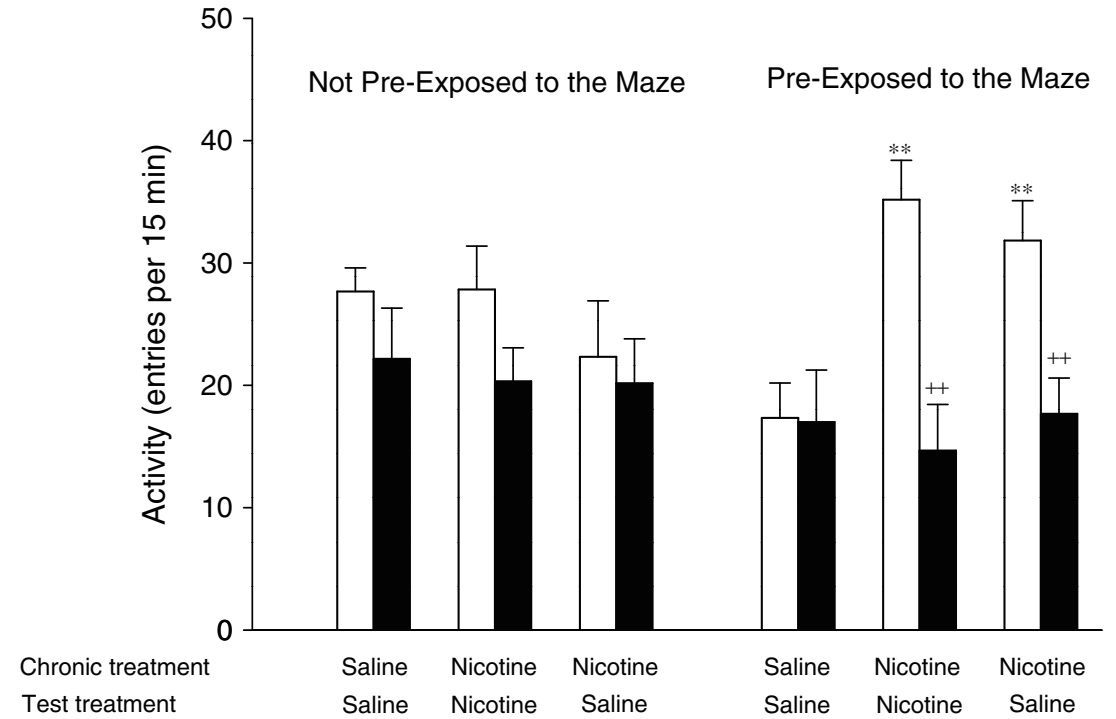

Fig. 7 Effects of conditioning on locomotor responses to nicotine in a cross maze. One group of rats were pretreated with daily injections (s.c.) of saline or nicotine $(0.4 \mathrm{mg} / \mathrm{kg})$ for 16 days (chronic treatment) and returned to their home cages after each injection (non pre-exposed rats). On test days, the rats $(N=6$ per group) were pretreated with MPEP $(5.0 \mathrm{mg} / \mathrm{kg}$, i.p. filled columns) or its saline vehicle (open columns), using a counter-balanced experimental design, $30 \mathrm{~min}$

to the maze with saline injections. This was not true for animals not habituated to the maze after each injection of nicotine. Moreover, for the rats treated with saline on the test day, there was a significant three-way interaction between the effects of MPEP on entries, habituation to the maze and the treatment the animals received during habituation (MPEP $\times$ nicotine $\times$ habituation $F(1,20)=6.0$, $P<0.05)$. Post hoc analysis showed that MPEP reduced activity in the rats which had been habituated to the maze with nicotine (MPEP $\times$ nicotine $F(1,10)=8.9, P<0.05$ ) but had no significant effects in rats which had been treated habitually with saline or rats which had been repeatedly treated with nicotine but not habituated to the maze after each injection.

\section{Discussion}

The initial results presented in this paper have confirmed those of previous studies (Paterson et al. 2003; Tessari et al. 2004; Palmatier et al. 2007) which have shown that the administration of mGluR5 receptor antagonists reduces the intravenous self-administration of nicotine. The present study has shown that this effect of MPEP seems to be dosedependent with the highest dose of MPEP tested, eliciting a complete inhibition of responding for the drug in many of the rats. The results imply that responding for nicotine depends upon the stimulation of mGluR5 receptors within before they were given a second s.c. injection (test treatment) of saline or nicotine. The same experimental design on the test days was used for a second group of rats which were pre-exposed to the maze by testing them for 15 min per day after each of their chronic injections. The data are expressed as means \pm SEM. Significantly different from habituated to the maze with saline ${ }^{* *} P<0.01$. Significantly different from rats given i.p. saline on the test day $++P<0.01$

the brain, although higher doses of the drug also exert other effects which could be implicated in the psychopharmacological responses to MPEP. For example, MPEP can inhibit the neuronal transporter for norepinephrine (Heidbreder et al. 2003). However, the dose of MPEP used to evoke this effect in vivo $(30 \mathrm{mg} / \mathrm{kg}$, i.p.) was higher than any of the doses employed in this study. Furthermore, previous studies which have investigated the effects of MPEP on nicotine self-administration have employed doses up to $10 \mathrm{mg} / \mathrm{kg}$ and interpreted their findings as evidence for a role of mGluR5 receptors (Paterson et al. 2003; Tessari et al. 2004; Palmatier et al. 2007). The effects of MPEP on responding for nicotine in the IVSA paradigm could have reflected a general inhibition of the effects of nicotine on behavioural activity in general since it reduced responding on both levers. This explanation seems unlikely because MPEP had no significant effects on the locomotor stimulant properties of nicotine when measured in an environment to which the animals which had been extensively habituated on the test day. Under these conditions, the stimulant response to nicotine can be observed following both the acute and repeated administration of the drug. Furthermore, injections of MPEP did not attenuate responding in animals trained to lever-press for a palatable food reward, indicating that the drug does not evoke a generalised reduction in responding for all reinforcers in this operant procedure. This observation could reflect a simple difference in efficacy as rewards of the two reinforcers, the sweetened food reward providing 
a significantly more powerful reinforcer than nicotine. However, there are also differences in the neurobiology underpinning responding for the two reinforcers. Operant responding for nicotine is attenuated substantially by lesions of the DA neurones which project to the NAc and by pharmacological interventions which inhibit the activity of these neurones (Corrigall et al. 1992, 1994). By contrast, responding for food rewards is not attenuated significantly by similar treatments (Salamone et al. 2001). Thus, it seems equally plausible that the differential effects of MPEP on responding for the two reinforcers could reflect the neurobiological substrate through which the compound exerts its effects on nicotine self-administration.

When compared with other stimulant drugs of dependence, the reinforcing properties of nicotine are relatively weak and do not appear to provide an adequate explanation for the powerful addiction to tobacco smoke experienced by many smokers (Caggiula et al. 2001; Balfour 2006). Thus, it has been proposed that the powerful reinforcing properties of tobacco smoke may depend, in part, on the ability of nicotine to enhance the reinforcing properties of other weak reinforcers present in the smoke (Rose et al. 2000, 2006; Donny et al. 2003; Palmatier et al. 2006; Balfour 2004, 2006). Donny et al. (2003) have previously used a yoked design to show that non-contingent infusions of small doses of nicotine, delivered throughout the experimental session, enhance responding for a weak reinforcer. The data reported in the present study have extended these earlier findings by showing that a response-enhancing effect, in a similar paradigm, can also be seen in animals given nicotine as a single injection prior to the session. It seems clear that the animals are responding for the reinforcer and not exhibiting a habitual response on the active lever because reversing the outcome of pressing the levers also reverses the lever which is pressed preferentially. The results have shown that this mode of responding is also sensitive to antagonism of mGluR5 receptors. However, in this experiment, the effects of MPEP were not restricted to the rats trained with nicotine since the compound also dosedependently attenuated the lower levels of responding observed in the saline-treated rats. Thus, a parsimonious explanation for the data posits that MPEP preferentially attenuates responding in paradigms and contexts in which nicotine facilitates responding.

At the higher dose tested, pretreatment with MPEP abolished responding for nicotine in many of the rats tested in the IVSA protocol. This observation suggests that the drug may not only influence nicotine-taking behaviour but may also inhibit nicotine-seeking behaviour evoked by the presentation of contextual cues related to the availability of the drug. This explanation is consistent with the evidence that environmental and contextual cues repeatedly paired with the presentation of drugs, including nicotine, are thought to play a central role in eliciting drug-seeking and drug-taking behaviour (Spealman et al. 1999; Arroyo et al. 1998; Schenk and Partridge 2001; Caggiula et al. 2002; Le Foll and Goldberg 2009). It is also consistent with the results of the experiment reported in the present study in which the locomotor responses to nicotine were investigated in animals treated repeatedly with the drug. In experiments performed with animals tested during the first $15 \mathrm{~min}$ of exposure to the cross maze, sensitised responses to nicotine were only observed in the animals in which the drug had previously been paired with exposure to the maze. MPEP had no significant effects on the activity measured in animals which were unfamiliar with the maze or salinetreated animals which had been habituated to the apparatus. By contrast, MPEP inhibited the activity of the nicotinetreated animals in which the injections had been repeatedly paired with the maze. The results suggest that MPEP may preferentially attenuate conditioned responding evoked by exposure to contextual cues previously paired with nicotine. The hypothesis is supported further by the evidence that MPEP also attenuated the conditioned hyperactivity of the nicotine-pretreated animals when they were tested in the maze after an injection of saline. It also provides a possible explanation for the effects of MPEP in the operant studies in which it attenuated responding on both the active and inactive levers. This outcome might be predicted if the drug attenuates the influence of contextual cues on behaviour in general rather than a selective effect on specific behavioural responses related to reinforcement.

In summary, this study has confirmed the results of previous studies which have shown that blockade of mGluR5 receptors with MPEP attenuates responding for nicotine in an IVSA paradigm. They have extended these observations to show that pretreatment with MPEP also attenuates the response-enhancing effects of nicotine in a paradigm in which responding is reinforced by a weak reward. Thus, the data suggest that blockade of the receptors attenuates the reinforcing properties of nicotine. However, this simple interpretation may need to be treated with some caution. The psychopharmacological mechanisms underpinning dependence upon nicotine are complex and involve interactions between the drug and contextual stimuli and conditioned reinforcers associated with presentation of the drug which seem to play an especially important role in nicotine self-administration in rodents (Caggiula et al. 2002; Chaudhri et al. 2006a, b). The data presented here suggest that this component of the dependence may be preferentially sensitive to mGluR5 receptor blockade. If the hypothesis is true, it suggests that stimulation of mGluR5 receptors may also play a significant role in provoking drug-seeking behaviour evoked by exposure to contextual cues and, putatively, tobacco cravings in habitual smokers exposed to cues associated 
with their smoking habit. The data support the conclusion that antagonists at mGluR5 receptors may prove valuable as aids to smoking cessation, although this conclusion needs to be tempered by the evidence that these antagonists may exacerbate the consequences of nicotine withdrawal (Liechti and Markou 2007).

Acknowledgements The study was supported by grants from Cancer Research UK and the Wellcome Trust.

Open Access This article is distributed under the terms of the Creative Commons Attribution Noncommercial License which permits any noncommercial use, distribution, and reproduction in any medium, provided the original author(s) and source are credited.

\section{References}

Arroyo M, Markou A, Robbins TW, Everitt BJ (1998) Acquisition, maintenance and reinstatement of intravenous cocaine selfadministration under a second-order schedule of reinforcement in rats: effects of conditioned cues and continuous access to cocaine. Psychopharmacology 140:331-344. doi:10.1007/ s002130050774

Bäckström P, Hyytiä P (2007) Involvement of AMPA/kainate, NMDA, and mGlu5 receptors in the nucleus accumbens core in cue-induced reinstatement of cocaine seeking in rats. Psychopharmacology 192:571-580. doi:10.1007/s00213-0070753-8

Balfour DJ (2004) The neurobiology of tobacco dependence: a preclinical perspective on the role of the dopamine projections to the nucleus accumbens. Nicotine Tob Res 6:899-912

Balfour DJ (2006) Complementary roles for the accumbal shell and core in nicotine dependence. In: Bock G, Goode J (eds) Understanding nicotine and tobacco addiction (Novartis Symposium 272). Wiley, Chichester, pp 96-115

Benowitz NL (2009) Pharmacology of nicotine: addiction, smokinginduced disease, and therapeutics. Ann Rev Pharmacol Toxicol 49:57-71. doi:10.1146/annurev.pharmtox.48.113006.094742

Burns LH, Everitt BJ, Kelley AE, Robbins TW (1994) Glutamatedopamine interactions in the ventral striatum: role in locomotor activity and responding with conditioned reinforcement. Psychopharmacology 115:516-528

Caggiula AR, Donny EC, White AR, Chaudhri N, Booth S, Gharib MA, Hoffman A, Perkins KA, Sved AF (2001) Cue dependency of nicotine self-administration and smoking. Pharmacol Biochem Behav 70:515-530. doi:10.1016/S0091-3057(01)00676-1

Caggiula AR, Donny EC, White AR, Chaudhri N, Booth S, Gharib MA, Hoffman A, Perkins KA, Sved AF (2002) Environmental stimuli promote the acquisition of nicotine self-administration in rats. Psychopharmacology 163:230-237. doi:10.1007/s00213$002-1156-5$

Chaudhri N, Caggiula AR, Donny EC, Palmatier MI, Liu X, Sved AF (2006a) Complex interactions between nicotine and nonpharmacological stimuli reveal multiple roles for nicotine in reinforcement. Psychopharmacology 184:353-366. doi:10.1007/s00213-0050178-1

Chaudhri N, Caggiula AR, Donny EC, Booth S, Gharib M, Craven L, Palmatier MI, Liu X, Sved AF (2006b) Operant responding for conditioned and unconditioned reinforcers in rats is differentially enhanced by the primary reinforcing and reinforcementenhancing effects of nicotine. Psychopharmacolgy 189:27-36. doi:10.1007/s00213-006-0522-0
Cohen C, Perrault G, Griebel G, Soubrié P (2005) Nicotine-associated cues maintain nicotine-seeking behavior in rats several weeks after nicotine withdrawal: reversal by the cannabinoid (CB1) receptor antagonist, rimonabant (SR141716). Neuropsychopharmacology 30:145-155. doi:10.1038/sj.npp.1300541

Corrigall WA, Franklin KB, Coen KM, Clarke PB (1992) The mesolimbic dopaminergic system is implicated in the reinforcing effects of nicotine. Psychopharmacology 107:285-289

Corrigall WA, Coen KM, Adamson KL (1994) Self-administered nicotine activates the mesolimbic dopamine system through the ventral tegmental area. Brain Res 653:278-284. doi:10.1016/ 0006-8993(94)90401-4

Crombag HS, Bossert JM, Koya E, Shaham Y (2008) Contextinduced relapse to drug seeking: a review. Philos Trans R Soc Lond B Biol Sci 363:3233-3243. doi:10.1098/rstb.2008.0090

Donny EC, Chaudhri N, Caggiula AR, Evans-Martin FF, Booth S, Gharib MA, Clements LA, Sved AF (2003) Operant responding for a visual reinforcer in rats is enhanced by noncontingent nicotine: implications for nicotine self-administration and reinforcement. Psychopharmacology 169:68-76. doi:10.1007/ s00213-003-1473-3

Heidbreder CA, Bianchi M, Lacroix LP, Faedo S, Perdona E, Remelli R, Cavanni P, Crespi F (2003) Evidence that the metabotropic glutamate receptor 5 antagonist MPEP may act as an inhibitor of the norepinephrine transporter in vitro and in vivo. Synapse 50:269-276

Henningfield JE, Shiffman S, Ferguson SG, Gritz ER (2009) Tobacco dependence and withdrawal: science base, challenges and opportunities for pharmacotherapy. Pharmacol Ther 123:1-16. doi:10.1016/j.pharmthera.2009.03.011

Le Foll B, Goldberg SR (2009) Effects of nicotine in experimental animals and humans: an update on addictive properties. Handb Exp Pharmacol 192:335-367. doi:10.1007/978-3-540-69248-5_12

Liechti ME, Markou A (2007) Interactive effects of the mGlu5 receptor antagonist MPEP and the mGlu2/3 receptor antagonist LY341495 on nicotine self-administartion and reward deficits associated with nicotine withdrawal in rat. Eur $\mathrm{J}$ Pharmacol 554:164-174

Martin-Fardon R, Baptista MA, Dayas CV, Weiss F (2009) Dissociation of the effects of MTEP [3-[(2-methyl-1, 3-thiazol-4-yl)ethynyl] piperidine] on conditioned reinstatement and reinforcement: comparison between cocaine and a conventional reinforcer. J Pharmacol Exp Ther 329:1084-1090. doi:10.1124/jpet.109.151357

Palmatier MI, Evans-Martin FF, Hoffman A, Caggiula AR, Chaudhri N, Donny EC, Liu X, Booth S, Gharib M, Craven L, Sved AF (2006) Dissociating the primary reinforcing and reinforcementenhancing effects of nicotine using a rat self-administration paradigm with concurrently available drug and environmental reinforcers. Psychopharmacology 184:391-400. doi:10.1007/ s00213-005-0183-4

Palmatier MI, Liu X, Donny EC, Caggiula AR, Sved AF (2007) Metabotropic glutamate 5 receptor (mGluR5) antagonists decrease nicotine seeking, but do not affect the reinforcement enhancing effects of nicotine. Neuropsychopharmacology 33:2139-2147. doi:10.1038/sj.npp.1301623

Paterson NE, Semenova S, Gasparini F, Markou A (2003) The mGluR5 antagonist MPEP decreased nicotine self-administration in rats and mice. Psychopharmacolgy 167:257-264. doi:10.1007/ s00213-003-1432-z

Rose JE (2006) Nicotine and non nicotine factors in cigarette addiction. Psychopharmacology 184:274-285. doi:10.1007/ s00213-005-0250-x

Rose JE, Behm FM, Westman EC, Johnson M (2000) Dissociating nicotine and nonnicotine components of cigarette smoking. Pharmacol Biochem Behav 67:71-81. doi:10.1016/S0091-3057 (00)00301-4 
Salamone JD, Wisniecki A, Carlson BB, Correa M (2001) Nucleus accumbens dopamine depletions make animals highly sensitive to high fixed ratio requirements but do not impair primary food reinforcement. Neuroscience 105:863-870. doi:10.1016/S03064522(01)00249-4

Schenk S, Partridge B (2001) Influence of a conditioned light stimulus on cocaine self-administration in rats. Psychopharmacology 154:390-396. doi:10.1007/s002130000608

Spealman RD, Barrett-Larimore RL, Rowlett JK, Platt DM, Khroyan TV (1999) Pharmacological and environmental determinants of relapse to cocaine-seeking behavior. Pharmacol Biochem Behav 64:327-336. doi:10.1016/S0091-3057(99)00049-0

Tessari M, Pilla M, Andreoli M, Hutcheson DM, Heidbreder CA (2004) Antagonism at metabotropic glutamate 5 receptors inhibits nicotine- and cocaine-taking behaviours and prevents nicotine-triggered relapse to nicotine-seeking. Eur J Pharmacol 499:121-133. doi:10.1016/j.ejphar.2004.07.056

You ZB, Wang B, Zitzman D, Azari S, Wise RA (2007) A role for conditioned ventral tegmental glutamate release in cocaine seeking. J Neurosci 27:10545-10555. doi:10.1523/jneurosci. 2967-07.2007 